WellBeing International

WBI Studies Repository

$11-2007$

\title{
Considerations for determining optimal mouse caging density
}

\author{
Charmaine Foltz \\ National Institutes of Health \\ Larry Carbone \\ University of California - San Francisco \\ David DeLong \\ VA Medical Center - Minneapolis \\ Bernard E. Rollin \\ Colorado State University - Fort Collins, bernard.rollin@colostate.edu \\ Pascalle Van Loo \\ Utrecht University
}

See next page for additional authors

Follow this and additional works at: https://www.wellbeingintlstudiesrepository.org/labrawel

Part of the Animal Experimentation and Research Commons, Animal Studies Commons, and the Bioethics and Medical Ethics Commons

\section{Recommended Citation}

Foltz, C., Carbone, L., DeLong, D., Rollin, B. E., Van Loo, P., Whitaker, J., \& Wolff, A. (2007). Considerations for determining optimal mouse caging density. Lab Animal, 36(10), 40.

This material is brought to you for free and open access by WellBeing International. It has been accepted for inclusion by an authorized administrator of the WBI Studies Repository. For more information, please contact wbisr-info@wellbeingintl.org.

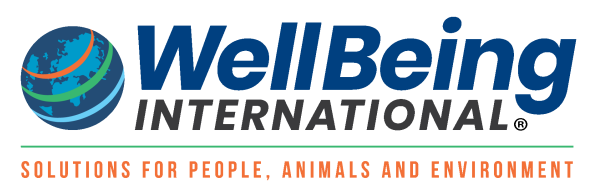




\section{Authors}

Charmaine Foltz, Larry Carbone, David DeLong, Bernard E. Rollin, Pascalle Van Loo, Julia Whitaker, and Axel Wolff 


\title{
Considerations for determining optimal mouse caging density
}

\author{
Charmaine Foltz, DVM ${ }^{1}$, Larry Carbone, DVM, PhD' , David DeLong, DVM ${ }^{3}$, Bernard E. Rollin,
} $\mathrm{PhD}^{4}$, Pascalle Van Loo, $P h D^{5}$, Julia Whitaker, $D V M^{6}$ \& Axel Wolff, $D V M^{7}$

At the 2006 National Meeting of the American Association of Laboratory Animal Science, a panel discussed the question of what constitutes optimal or acceptable housing density for mice. Though there is a consensus that present guidelines are somewhat arbitrarily defined, scientific research has not yet been able to provide clear recommendations for amending them. Speakers explored the many factors that influence decisions on mouse housing, including regulatory requirements, scientific data and their interpretation, financial considerations and ethical concerns. The panel largely agreed that animal wellbeing should be the measure of interest in evaluating housing density and that well-being includes not only physical health, but also animals' behavior, productivity and preference.

Despite numerous experimental studies ${ }^{1-20}$, no consensus has emerged regarding optimal—or even minimally acceptable-cage space for rodents. After years of deliberation, the Council of Europe recently finalized regulations that increased minimum space requirements for several lab animal species. The additional space is intended to allow for the addition of structural elements to enable animals to express their typical behaviors, which can help to minimize stress ${ }^{21}$. In contrast to these new European regulations, recent publications from groups in the US suggest that less space might be beneficial for mice ${ }^{22-26}$.

The Guide for the Care and Use of Laboratory Animals (Guide) defines standards for mouse cage density but allows for variation from those standards in certain circumstances ${ }^{26}$. As a result, mouse housing densities may differ substantially between or even within institutions. Many institutions allow breeding schemes that result in cage densities that are higher than the standard densities given in the Guide. These practices are often entrenched, and researchers are reluctant to change them without proof that they are detrimental.

Europe and the US approach the topic of cage density from different perspectives. In Europe, the space guidelines suggested by regulators are viewed as minimum requirements, whereas in the US, the caging density standards are considered to be optimal. Additionally, European regulations focus not only on the amount of space provided, but also on the quality of that space.

In a panel session on mouse housing density at the 2006 National Meeting of the American Association for Laboratory Animal Science (AALAS) in Salt Lake City, UT, participants explored some of the discrepancies in caging density standards and evaluated the rationale for decreasing mouse floor space requirements in light of animal welfare, a factor that weighed heavily in the development of the European regulations. This article summarizes the presentations made at that session.

\section{REGULATORY CONSIDERATIONS}

Axel Wolff, DVM

Division of Compliance Oversight, OLAW, National Institutes of Health, Bethesda, MD

The Public Health Service Policy on Humane Care and Use of Laboratory Animals (PHS Policy) ${ }^{27}$ requires institutions to use the Guide as a basis for developing and implementing institutional programs for activities involving animals. This renders the Guide's technical standards federally enforceable. PHS Policy enables a degree of flexibility, however, in promoting a system

\footnotetext{
${ }^{1}$ Division of Veterinary Resources, National Institutes of Health, Bethesda, MD. ${ }^{2}$ University of California San Francisco, San Francisco, CA. ${ }^{3}$ Veterinary Medical Unit, VA Medical Center, Minneapolis, MN. ${ }^{4}$ Colorado State University, Fort Collins, CO. ${ }^{5}$ Utrecht University, The Netherlands. ${ }^{6}$ Department of Pathology and Laboratory Medicine, Division of Laboratory Animal Medicine, University of North Carolina, Chapel Hill, NC. ${ }^{7}$ Division of Compliance Oversight, OLAW, National Institutes of Health, Bethesda, MD. Correspondence should be addressed to C.F. (foltzc@mail.nih.gov).
} 
of institutional self-regulation with oversight by the IACUC. This allows institutions to incorporate professional judgment and performance outcome when defining institutional standards. Thus, as far as cage density is concerned, the Guide's requirements should be regarded as the standard, and any deviation from these requirements must be scientifically justified and approved by the IACUC.

The 1996 Guide is based on published data, expert opinion, scientific principles and known practices of high-quality animal care. The Office of Laboratory Animal Welfare (OLAW) expects institutions to adhere to the most recent version of the Guide. In 2006, in response to requests for a revision of the Guide, NIH issued a Request for Information to assess the need for updating the general standards currently in place. A working group of scientists and veterinarians from PHS agencies reviewed the submissions received. The group found no scientific evidence to warrant revising the performance standards of the 1996 Guide but recommended that the Guide become a living, web-based document with appendices that could be periodically revised with current references for best practices, new topics and validated hypothesis-driven research. New references would be included only after critical review for scientific validity. These recommendations were shared with the Institute of Laboratory Animal Resources Council and were summarized in Notice number NO7-00-07016 (http://grants2.nih.gov/grants/guide/notice-files/ NOT-OD-07-016.html).

As outlined in the guidance on deviations from cage density standards provided by OLAW in the 'Frequently Asked Questions' section of its web page (http://grants. nih.gov/grants/olaw/faqs.htm\#useandmgmt_10), modifications to the Guide's standards must have scientific or veterinary justification, must receive IACUC approval and must be project-specific rather than programwide. This guidance emphasizes that adjustments to the Guide cannot be based on considerations unrelated to animal welfare, including space restriction, convenience and cost. OLAW also clarifies that parents with pups can be considered a single entity until pups begin to move around the cage. PHS Policy authorizes OLAW to review and approve or deny waivers to the Policy. Institutions are required to report any serious deviation from the provision of the Guide to OLAW.

\section{EXAMINING SCIENTIFIC STANDARDS Larry Carbone, DVM, PhD

When analyzing housing standards for any lab animal species, it is useful to examine how scientific research has affected the development of existing space requirements and to envision how science can be bet- ter used to this end. Since the early 1960s, the Animal Welfare Act (AWA ${ }^{28}$ and the Guide have included recommendations on cage size. These regulations and guidelines have not always been tied to science, but their scientific basis has improved with each new edition of the AWA and the Guide.

Ideally, animal care guidelines would be based purely on objective scientific data. But data require interpretation by human beings whose judgment is influenced by theoretical assumptions, politics, ethics and values. This situation is complicated further by the need to extrapolate limited data from one cohort of animals to others of different species, strains and ages.

The following case study demonstrates some of the challenges in using science to prescribe cage sizes ${ }^{29}$. Between 1960 and 1985, the AWA recommended allocating $90 \mathrm{in}^{2}$ of floor space for each adult guinea pig weighing more than $350 \mathrm{~g}$ and twice as much space $\left(180 \mathrm{in}^{2}\right)$ for each breeding guinea pig. In 1986, the United States Department of Agriculture (USDA) called for scientific submissions for a planned revision of the AWA. They received 36,000 responses but only two sets of scientific data, one of which concerned guinea pig space requirements ${ }^{30}$. The study examined 'harems' of 4-7 pigs, each including one vasectomized male. The group sizes represented the standard at the time for breeding animals. Each group was placed in a cage with the amount of space recommended for four breeding guinea pigs. The results showed that the guinea pigs associated with each other and spent 75$80 \%$ of their time in $47 \%$ of the cage space. The study concluded that breeding groups do well with $60 \%$ of the space recommended at the time. On the basis of this paper's conclusions, the USDA decreased their cage size requirements and removed the increased space requirement for breeding guinea pigs.

How well did the study determine the space needs of guinea pigs? The authors made some unstated assumptions that warrant examination. First, they assumed that the space used by the guinea pigs only $20-25 \%$ of the time was not important to their welfare. This could be analogous to concluding that a person's bedroom is not important to his welfare because he spends only 6 hours a day there. The USDA has often ruled that infrequently performed behaviors do not merit legal protection, without questioning whether these behaviors are important to the animal: in 1991, for example, they decided that dogs do not stand on their hind limbs frequently enough to mandate cages tall enough for that behavior $^{31}$. Although some infrequently performed behaviors probably are negligible, others, such as eating a meal, laying an egg or scratching an itch, may be quite important to the animal, despite taking only minutes a day to perform.

The researchers also assumed that a vasectomized 'breeding group' was a good model of a true breeding 
group. This may be true in terms of sexual behavior, but not in terms of reproductive behavior. For instance, a true breeding group's cage density increases with the birth of pups. Additionally, guinea pigs' social interactions may change when pups are present in the cage, or even with pregnancy. While the authors' hypothesis may be testable, their conclusions are questionable and the data are insufficient for informing science-based standards.

The USDA never stated its rationale for giving breeding guinea pigs twice as much space in the first place, making it difficult to conclude whether the study's findings addressed the USDA's original assumptions. Thus, although the resulting recommendation may have been perfectly appropriate, it cannot accurately be labeled 'science-based'.

\section{Evaluating data}

When attempting to define science-based standards for cage density and space, researchers can evaluate the following data: (i) environmental conditions (ammonia, $\mathrm{CO}_{2}$, noise and air flow); (ii) reproduction (fertility rate, embryo survival); (iii) health (growth, survival rates, respiration and bone density); (iv) physiological conditions ('stress' hormones such as cortisone or corticosterone, leukocyte count, heart rate, immune function, testosterone and prolactin); and (iv) behavior (gross measures such as aggression and cannibalism or more refined measures such as time budget, preference testing, demand (how hard the animal will work to obtain the preference), presence of stereotypies, reaction to a strange setting or other unknown animals and rearing effects).

Data assessment can depend on the purpose for which the standards are being created. If the guidelines focus on human benefit-getting the most out of the mice while using as little space and money as possiblethen data concerning growth, reproduction and possibly health (if healthier mice lead to better experimental data) might suffice. If the guidelines strive to consider animal welfare, they must focus on indicators of mouse distress, preference, physiology, health and behavior.

Different methods of data assessment often yield similar conclusions. For example, toxic levels of ammonia buildup can cause health problems that may result in distressful behavior. Aversive ammonia fumes can also directly lead to distressful behavior and cause mice to release stress hormones, both of which may result in impaired health. Therefore, we will be able to conclude that ammonia above a certain concentration is harmful to mice, whether we examine health, behavior or physiology.

There may be instances in which a particular environment scores well by some tests and less well by others. For example, mice may choose a social setting that can help them achieve better reproductive opportunities but also lead them to more aggressive encounters. Mice may also make choices that affect them aversely, such as eating unhealthy food, or may actively avoid an environment that does not seem to affect them physiologically. Additionally, not all testing modalities are equally sensitive for addressing a particular welfare question. As a general approach, to make a sound policy recommendation it seems best to study as many different types of data as possible and to critically examine any differences found.

It is also important to consider the sample when drawing conclusions from data. A study of same-sex animal groups might not apply to breeding animals. Cage requirements may also vary between strains and for transgenic mice. A study that considers a population as a whole without distinguishing between individuals may miss the different experiences of dominant and submissive animals.

To obtain accurate conclusions, studies should identify the range of cage densities in which alterations in mouse behavior are detectable at the extremes. Only thus can a lack of effect be believable for intermediate conditions. If a mouse shows the same behavior in $6 \mathrm{in}^{2}$ and in $3 \mathrm{in}^{2}$, it is possible that both cage sizes are too large or too small, or that the data collection is somehow flawed. One way to include data on extreme conditions is to refer to studies of mice in expansive naturalistic environments or in severely restricted or averse environments. This may, however, lead to problems related to reliance on historical or out-of-study control groups.

The Guide tries to consider both human benefit and animal welfare, reflecting its authors' beliefs that, for the most part, happy, healthy animals make the best subjects for research. In some cases, however, performance standards such as species-specific behavior are poorly defined in the Guide, which can lead to conflict between certain recommendations and the actual cage sizes the Guide proposes (engineering standards). For instance, engineering standards state that rabbit cages should be 14 in high, which does not meet the requirement to allow an adult rabbit to rear up on her hind legs (a 'typical posture'). European and Australian guidelines contain more precisely defined performance standards, which include social interaction, rearing, hopping, running and digging. Like American guidelines, however, these standards seem to be somewhat arbitrarily defined. For example, rabbits are given enough space for three hops. Why recommend three hops instead of one (which is the American standard) or 30? The guidelines do not cite a scientific source to justify the recommendation.

\section{A critical analysis of recent research}

One report from researchers at the Jackson Laboratory ${ }^{25}$ exemplifies the importance of careful data interpretation. The project, which was funded 
by the PHS, was published in a leading US journal of laboratory animal science. It is an ambitious study of a large number of animals that simultaneously combines several different methods to assess animal well-being. This is a great advantage over studies that focus solely on reproduction, medical, physiological or behavioral parameters. As a result, this study will probably be an important resource for the next revision of the Guide. But how well does it meet our needs for setting science-based standards?

The investigators evaluated three different sizes of ventilated cages that housed 4-35 mice per cage. They found that all mice had a high survival rate and were not aggressive. The number of females with hair loss increased with increased density, as did cage temperature and ammonia concentration. Mice had no detectable histopathological damage to their respiratory tracts.

The authors concluded that mice tolerated the ammonia concentrations found and that animals should not be housed at the highest density tested. They do not explicitly state the reasons for these conclusions, though they seem to be based on histopathological rather than on behavioral criteria.

As in the guinea pig study described above, the authors made assumptions that would be better framed as testable hypotheses for future studies. They assumed that mice tolerate ammonia concentrations lower than those that cause histopathological lesions; this may not be the case. They also assumed that a 5-min observation per day in addition to a pelt exam for lasting wounds was enough to reflect aggression. These assumptions may have led to false negative findings, and yet the authors caution the precise opposite: that the statistically significant differences they did find may not have biological significance. In addition, the study did not include preference testing, nor did it evaluate stereotypic behavior or corticosterone concentrations. As a result, though the study presents a wide range of seemingly sound data, problems of interpretation will diminish its usefulness for setting policy.

The authors of the next Guide must decide what to do with such studies. Should a single study stand alone to shape policy, as did the guinea pig study for the AWA regulations? How much more verification is required to establish a study's findings, and their interpretation, as sufficient for shaping policy?

The challenge does not end with the answers to these questions. Even if we understand conclusively what animals 'want', giving it to them may cost time money and effort. How strong must an animal preference or aversion be to warrant an amendment to the Guide? In short, though robust data and sound interpretation are crucial, there is no single scientific study that can answer that ethical question.

\section{CONSIDERING ADDITIONAL FACTORS Pascalle Van Loo, PhD Utrecht University, The Netherlands}

Mouse cage density can be defined in two different ways: as the amount of floor space per mouse or as the number of mice in a cage. Though the Guide addresses only the first interpretation, the second may be more important to mouse welfare. The number of mice that can be put in a cage can depend on any of the following factors: strain, age, gender, length of experiment, genetic alteration, level of inbreeding, past experience of the mice, experimental procedures, familiarity of the mice with each other and the order of testing.

Socially housed mice influence one another behaviorally: they may have an increased pain threshold, for example, or cope better with stressful experimental procedures $^{32}$. Conversely, they may become more aggressive, or one mouse might monopolize the food source or enrichment.

In a study performed in our laboratory, we found that aggression in male mice increased in direct relation to the size of their group ${ }^{19}$. The study also found that although cage size had some effect on aggression, the size of the group was more important.

It is not only the size of the group that matters, but also the composition of the group. One study investigated the common practice of mixing mouse litters to obtain equal group sizes ${ }^{3}$. The researchers found that male and female mice in undisturbed litters thrived better than those in disturbed litters, regardless of the size of the litter. Variance of body weight was higher in disturbed litters than in undisturbed litters, demonstrating that a practice intended to standardize litters had the opposite effect. This illustrates that strict enforcement of space requirements is not necessarily in the animals' best interest. Another example of the influence of group composition and size is the Whitten effect, in which estrus is synchronized among grouphoused females ${ }^{33}$.

Group-housed mice are also affected by the order in which they are tested, which can influence experimental outcome. One such example is a study of stress-induced hyperthermia ${ }^{34}$. Researchers removed mice one at a time from their group and measured their temperature by insertion of a rectal probe. Owing to the stress response to handling, the temperature was lowest in the first mouse removed from the cage and rose in each subsequent mouse. In another study, carried out in our laboratory, in which mice were housed in groups of three, basal corticosterone concentrations were lowest in the first mouse taken out of the group and rose in each subsequent mouse. In a different study in which the same mice underwent a modified holeboard test, corticosterone concentrations declined between the first and third mouse tested (Steenmans, R.J.M., Baumans, V., Ohl, F. and \& Van Loo, P.L.P., unpublished data). 
Financial considerations also play a part in decisions about rodent housing. Though it may seem that housing more mice in a cage can reduce costs, this may not actually be the case. Researchers may need to use more mice in an experiment because increased density can cause more variation between test subjects. In addition, if there is a problem with a single cage, more mice per cage means more mice will have to be replaced. Researchers should therefore approach financial questions carefully and maintain a balance between economics and ethics.

There are sophisticated methods of reducing the number of animals needed and improving the quality of the science without increasing costs, which may also benefit animal welfare. Let us consider, for example, a study of the effect of four different drug treatments on tumor growth. Because group size and composition might influence tumor growth and mouse survival, it may be better to house four mice per cage, with each mouse receiving a different treatment, instead of separating the mice according to treatment group. In this model, all groups would have a similar composition, and costs would not be affected. The benefits of more sophisticated experimental designs for controlling extraneous variables have been explored in detail in several studies ${ }^{35,36}$.

How can new guidelines incorporate these additional factors? I would propose that instead of limiting ourselves to the standards in the Guide, we keep an open mind and completely reconsider our approach to determining optimal mouse housing density.

\section{CURRENT RESEARCH \\ Julia Whitaker, DVM \\ Department of Pathology and Laboratory \\ Medicine, Division of Laboratory Animal Medicine, University of North Carolina, Chapel Hill, NC}

This section briefly describes a study aimed at evaluating the effect of cage size on reproductive characteristics of breeding trios of C57BL/6 mice and on the behavior of their offspring ${ }^{37}$. We housed the breeding groups either in standard cages ( 82 in $^{2}$ of floor space) or in large cages (124 in ${ }^{2}$ of floor space). We maintained air flow at 75 changes per hour, changed cages every two weeks and provided enrichment (PVC and nesting material). We evaluated the following reproductive parameters: (i) litter size; (ii) litter survival; (iii) average pup weight at ages 7, 14 and $21 \mathrm{~d}$; and (iv) the interval between litter births. We tested the behavior of a subset of mice ( 12 females and 12 males) born to breeding trios in standard and large cages to evaluate whether differences in cage size during the neonatal period led to changes in anxiety-like behavior (elevated plus maze test) and activity in a novel environment (open field assay) before and after an aversive stimulus (intraperitoneal saline injection). We also evaluated mouse response to an acoustic startle stimulus. Previous work has suggested that the elevated plus maze and open field tests can indicate the effects of environmental and rearing conditions and that reactivity in the acoustic startle test might provide an index of stress early in development.

Based on the weight categories in the Guide, a standard cage can house five adults, two adults and up to nine pups, or three adults and six pups. A large cage can house 8 adults, 2 adults and up to 16 pups, or 3 adults and 13 pups. In our study, all breeding cages held 3 adults and 1-20 pups at any given time.

According to its recommendations for mice weighing less than $10 \mathrm{~g}$, the Guide requires $6 \mathrm{in}^{2}$ of floor space per pup from birth to weaning. In this study, after subtracting the amount of floor space required by three adults, the range of space available for pups was $1.9-37$ in $^{2}$ per pup in standard cages and 4-79 in ${ }^{2}$ in large cages. We observed no adverse effects of rearing pups with as little as $1.9 \mathrm{in}^{2}$ floor space. Though pups in large cages had at least two times more floor space than did pups in standard cages, we found no significant reproductive or behavioral differences between the groups.

We recognize that we have not measured all the possible effects on reproductive performance, behavior and mouse well-being and that we examined only one strain of mice (C57BL/6). A different strain of mice could have produced different results. It is also possible that the difference in the total cage floor space must be greater than $50 \%$ in order to detect a difference in reproductive or behavioral parameters. We can conclude that in the strain of mice that we examined and for the parameters we measured, there was no statistically significant difference between mice housed in standard cages or in cages that were $50 \%$ larger.

It is possible that the enrichment we provided (a Nestlet and PVC tunnel in all cages) masked effects of different cage sizes on mouse reproduction and behavior. We are currently examining the hypothesis that the environmental enrichment in a cage has a greater effect on breeding and behavior than cage size.

\section{CONSIDERING ETHICS \\ Bernard E. Rollin, PhD \\ Colorado State University, Fort Collins, CO \\ The push to increase cage density}

In the 1970s and 1980s the biomedical research community narrowly escaped losing substantial funding after it failed to take social and ethical concerns about laboratory animals seriously. A strong coalition pushed forward a well-supported federal bill known as the Research Modernization Act, which could have greatly decreased funds for animal research 
and increased the amount spent on finding alternatives to animals in research. Though the bill did not pass in its original form, it did inspire several modifications to the 1985 AWA, which chartered the Institutional Animal Care and Use Committee and ushered in an era of self-regulation. The biomedical community seemed to respond well to the demand to minimize animal pain and distress. But the recent movement to increase the number of animals housed in a standard cage indicates that the community has not learned its lesson.

The impetus for this movement is understandable, as research funds are declining while the cost of keeping animals is increasing and shows no signs of abating. Housing more animals in each cage can save equipment and labor. Thus, in an attempt to cut costs, many researchers are advocating an increase in cage density, providing arguments that may seem plausible on the surface but fail to stand up to closer scrutiny. Recent papers $^{22-24}$ point to the Guide as arbitrary, claiming its standards are based on professional judgment rather than experimental data. They conclude through research that it is acceptable to put more mice in cages, substantially reducing the amount of space per mouse. Their approach, however, fails to take into account many ethical and scientific considerations.

\section{Animal ethics}

St. Thomas Aquinas affirmed that animals were not direct objects of moral concern but nonetheless forbade cruelty to animals on the grounds that those who would be cruel to animals would eventually be cruel to humans. In the past, when animals were used primarily for agricultural purposes, this ethic was sufficient. Animals were protected by human self-interest: good husbandry was the key to agricultural success. Humans needed to keep animals in the best environment to meet their physical and psychological needs, protect them from predation and provide food, water and medical care. Laws protecting animals were vague, forbidding willful and unnecessarily cruel treatment not essential to "ministering to the necessities of man."

During the 1940s, animals began to be used in large numbers for research and testing, causing animals to suffer to an unprecedented degree. Anti-cruelty laws offered no protection, as they were not designed to address concerns related to new technology widely accepted by an industry. A demand was called forth for a new ethic for animals.

This emerging social ethic is reflected in the amount of legislation introduced to protect animals. More than 2,100 bills pertaining to animal welfare were introduced in 2004 in various states. Unlike humans, animals cannot have legal rights in the US and Europe because they are considered human property. In effect, laws for the protection of 'animal rights' are limitations on human use of property. US laws for lab animals demand pain control and environmental enrichment to provide conditions that are suited to the animal's biological nature. It has been argued that the conditions under which we keep animals cause more suffering to them than what we do to them in research. After all, only $10 \%$ of research protocols cause pain ${ }^{38}$, but laboratory animals spend their entire lives in an environment controlled by humans.

Assessment of animal welfare or suffering depends on subjective values and ethics. An agriculturalist may assume that if an animal puts on weight and reproduces, it has excellent welfare, though it may actually be miserable. The 1981 report of the Council for Agricultural Science and Technology ${ }^{39}$ states outright that if an animal is productive, it is well off. This may have been true when husbandry, welfare and productivity went hand in hand, but the statement no longer applies in an age when enhancements such as antibiotics and vaccines can improve an animal's productivity regardless of its well-being. Even physical health as it relates to welfare is ultimately subjective. Several publications that emerged in the 1980 s addressed this perception to some extent, emphasizing that an animal's 'experience' — encompassing fear, distress, boredom, crowding and more-is highly relevant to its welfare ${ }^{40-42}$.

In legislatively abolishing high-confinement production systems, Sweden and the European Union have demonstrated that the public perceives crowding of animals as an unacceptable condition. Indeed, it is common for people touring an animal facility to become shocked and upset at seeing animals in cages, particularly if many are crowded into a small space. Many people might be opposed to the suggestion that cage density can be increased, even if this approach is supported by scientific research. If scientists adopt these suggestions, they may diminish public confidence in the proposition that the welfare of research animals is properly assured. This emphasizes a central ethical issue: the concept of animal well-being does not rely solely on scientific fact. What scientists regard as 'acceptable' conditions may be very different from public opinion, and the public ultimately funds a good deal of research.

\section{The 'science' of animal welfare}

To establish an effective system for assessing animal well-being, we should critically examine the parameters we use. Lack of injury, for instance, is a necessary condition for welfare, but it is certainly not a sufficient condition. The measures made must not be arbitrary and must be evaluated logically in context of what they 'mean' to the mice.

Aggression is one criterion that can be used to evaluate well-being, and many factors can influence the accuracy of this measure. First, when is aggression 
measured? One observation period per day during light conditions, for instance, may not accurately reflect aggression, because this is the mouse's inactive period. Second, where are the humans when they are observing the mice? Mice that perceive humans as predators would tend to not show aggression in their presence, and would be more likely to flee or freeze. Third, what is considered an expression of aggression? Mice demonstrate numerous kinds of aggression, and scientists must distinguish between them. In particular, it is essential to distinguish between escalated fighting and mediated aggression occurring in normal hierarchies, which can be beneficial in establishing social relationships between mice. Additionally, crowded mice may suppress aggression as a result of disruption of territory formation.

In her classic pioneering work on animal welfare published in 1980, Animal Suffering: The Science of Animal Welfare ${ }^{40}$, Marion Dawkins demonstrated that no single parameter can conclusively tell us whether an animal is suffering. Dawkins suggests considering as many parameters as possible, including physiology, behavior, comparison with wild counterparts, productivity, animal preference and analogy to humans.

I would further augment Dawkins's point by saying that animal welfare studies do not pay enough consideration to individual differences. We tend to assume that all members of a given species are the same. There are substantial differences among individual higher primates, for example, in choosing environmental enrichment: an object that interests one animal may do absolutely nothing for another. Individual differences can exist within strains of mice and even among genetically identical mice. In addition, vast and increasing numbers of mice used in research are genetically modified, and it is not known whether findings from these mice can be extrapolated to other conventional strains of mice or even to the same strains at different ages or under different conditions.

Environment is another factor that scientists must take into account. Seemingly minor environmental variables can affect animals' physiological and metabolic condition to a degree that can influence research results. One study of male rats examined the effects of noninvasive procedures such as moving rats' cages or exposing them to ether for $1 \mathrm{~min}$ (ref. 43). Five minutes after the stressor, researchers evaluated several blood serum and physiological parameters (including corticosterone concentration, thyroid-stimulating hormone, heart rate and hemoglobin) and found that many were substantially affected. If something as seemingly trivial as moving a cage can elicit these effects, surely changes in housing density could have similar consequences.

A recent study reported that under natural conditions, the home territory for a house mouse (Mus $\mathrm{muscu}^{-}$ $l u s)$ is $3 \mathrm{~m}^{2}$ on average with a range of $2-80,000 \mathrm{~m}^{2}$ (ref. 32). This supports the thesis that the current guidelines are arbitrary but constitutes just as strong an argument against increasing mouse cage density. Increased cage density is already known to affect variables such as immunocompetence, susceptibility to radiation, parasites, infections and toxicity, sexual maturity, maternal behavior, infanticide and skin health ${ }^{44-47}$, and it may have many more unknown effects.

\section{Conclusions}

Any amendments to housing guidelines must be based on a sound concept of animal welfare, which includes concern for the animal's subjective experience and fulfills our ethical obligation to the animals we are using for our benefit. We must minimize animals' suffering and do as much as possible to allow them to live in accordance with their nature, instead of putting our own convenience first. Crowding animals in existing cages is emphatically not the solution. To understand what animals need, we must research many aspects of their nature, including behavior, physiology, preferences and behavior of wild counterparts. This approach is directly relevant to housing density, as well as to the broader issue of caring for animals used in research.

\section{DISCUSSION \\ David DeLong, DVM \\ Veterinary Medical Unit, VA Medical Center, Minneapolis, MN}

The Guide's recommendations for mouse cage density are being challenged on many fronts. The primary basis for the challenge is the claim that these standards are arbitrary and not based on experimental data. In an effort to develop science-based standards, investigators have undertaken a variety of studies intended to determine 'optimal' housing densities for mice.

Though it is appealing to think that a particular study or set of studies can provide enough information to determine optimal mouse housing density, the idea is probably flawed because so many complex factors are involved. Quantifiable factors that researchers can consider when designing such studies include physiological parameters, behavior and environmental quality. There is an enormous array of permutations and combinations that can be evaluated; indeed, virtually all publications that address housing density emphasize the need for additional studies. It remains unclear which measures are most important and how we should deal with conflicting data and strain-related differences. Existing studies are fraught with such limitations, and additional research will most likely complicate the picture even further. There is no definite indication as to when there will be enough information to establish new standards and conclude that they are scientifically valid. 
Even in the unlikely event that a set of well-designed objective studies yields a consensus about optimal housing density, there are subjective, non-quantifiable factors that must be considered before new standards can be adopted. Examples include cost, public perception of the research enterprise, safety and convenience for research staff, ease of performing husbandry tasks and ability to identify and assess individual animals. Little consideration has been given as to how heavily these subjective factors should weigh in comparison with the objective measures mentioned above.

Regardless of the ongoing controversy about appropriate housing density for mice, for the foreseeable future, the laboratory animal community will have to work with the recommendations in the current edition of the Guide. In the past most institutions followed these recommendations to the letter, but in recent years considerable disagreement has emerged regarding how rigidly these standards should be followed. Because the Guide emphasizes performance standards and allows exceptions to its recommendations with appropriate scientific justification, it may be tempting to conclude that one or two studies that advocate higher densities may be used to justify a departure from current Guide space recommendations. Taken to the extreme, such an approach could be used as justification for housing mice at twice the recommended density. This approach fails to acknowledge, however, that no single study or small group of studies addresses a sufficiently broad variety of parameters to permit sweeping conclusions. Furthermore, if institutions begin to set their own space requirements based on interpretation of selected studies, there is a danger of a loss of consistency among institutions. This would undermine recent trends toward harmonization of laboratory animal care practices. Since it is likely that housing density can influence the outcome of many types of experiments-behavior studies, for example-a patchwork of different housing standards could make interpretation and reproduction of experimental results more difficult.

Regulatory and oversight bodies such as OLAW and the Association for the Assessment and Accreditation of Laboratory Animal Care (AAALAC) International require institutions to comply with the Guide, and exceptions to its standards are usually expected to be protocol-specific rather than program-wide. If an institution allows a program-wide exception to the Guide, the IACUC must establish alternative standards and present evidence to support their validity. OLAW and AAALAC must, in turn, be satisfied that the supporting evidence is acceptable, though in view of the complexity of the cage space debate, it is not known how they could make that determination. Further complicating the picture is the potential for conflict of interest. Because a decision to increase housing density could substantially reduce costs, there is a possibility that an IACUC could be pressured to approve high-density housing with only marginal supporting evidence.

Present space recommendations are a 'one size fits all' standard, and some researchers argue that different standards may be appropriate for animals used for different purposes. This proposition requires careful examination. Consider, for example, animals in production colonies versus animals used for experimentation. It may seem logical that higher densities may be appropriate for production colonies, if the primary goal is to produce specific-pathogen-free animals at the lowest possible cost. The density at which animals are housed when very young may, however, affect the results of experiments done on them at a later age. For instance, housing density could substantially affect social and psychological development and subsequent performance in behavior testing paradigms. At a minimum, investigators should be aware of the density at which their animals were housed during all phases of life; optimally, such information should be reported in scientific publications.

Whether or not the space recommendations that appear in the Guide are ideal for mice, they at least provide an unambiguous standard. Therefore, all institutions should use them until an update of the Guide is published. To abandon these recommendations without substituting an alternative would be an invitation to chaos and confusion. The complexity of the issue and the far-reaching economic consequences make it prudent to have uniform standards that are accepted by the whole laboratory animal community. This is acknowledged by the Guide itself, which states, "Optimally, engineering and performance standards are balanced, thereby providing standards while allowing flexibility and judgment based on individual situations."

Reassessment and updating of the Guide's space recommendations is certainly overdue. Caging systems, husbandry practices and the role of environmental enrichment have evolved considerably since the last edition was published. Any new set of recommendations is bound to be imperfect, however, and will be based, at least to some extent, on subjective factors and 'professional judgment'. This is to be expected: many, if not most of the Guide's standards are formulated by consensus and have not been subject to rigid scientific scrutiny. Until the Guide provides new space recommendations, institutions should refrain from adopting their own standards unless a clear benefit to animal welfare can be demonstrated. Exceptions to current recommendations should be protocolspecific, scientifically justified and necessary for achieving the goals of the study. 


\section{ACKNOWLEDGMENTS}

The National AALAS seminar and panel session at which the topic of mouse cage density was discussed was cosponsored by the National Institutes of Health (NIH) Division of Veterinary Resources and the NIH National Center for Research Resources, Division of Comparative Medicine. We thank William Watson and Franziska Grieder for their support.

Disclaimer: The views expressed in "Regulatory Considerations" represent the position of OLAW/NIH, but the remainder of the contributions in this article does not represent official support or an endorsement by NIH or any government agency.

\section{COMPETING INTERESTS STATEMENT}

The authors declare no competing financial interests.

\section{Received 3 July; accepted 14 September 2007}

Published online at http://www.labanimal.com

1. Baumans, V., Stafleu, F.R. \& Bouw, J. Testing housing system for mice-the value of a preference test. Z. Versuchstierkd 29, 9-14 (1987).

2. Davidson, L.P., Chedester, A.L. \& Cole, M.N. Effects of cage density on behavior in young adult mice. Comp. Med. 57, 355-359 (2007).

3. Doolittle, D.P., Wilson, S.P. \& Gieseking, D. Effect of caging variables on body weight and weight gain in mice. $L a b$. Anim. Sci. 26, 556-561 (1976).

4. Eveleigh, J.R. Murine cage density: cage ammonia levels during the reproductive performance of an inbred strain and two outbred stocks of monogamous breeding pairs of mice. Lab. Anim. 27, 156-160 (1993).

5. Hackbarth, H., Bohnet, W. \& Tsai, P.P. Allometric comparison of recommendations of minimum floor areas for laboratory animals. Lab. Anim. 33, 351-355 (1999).

6. Haemisch, A. Voss, T. Gartner, K. (1994). Effects of environmental enrichment on aggressive behavior, dominance hierarchies, and endocrine states in male DBA/2J mice. Physiol. Behav. 56, 1041-1048.

7. Haemisch, A. \& Gartner, K. The cage design affects intermale aggression in small groups of male laboratory mice: strain specific consequences on social organization, and endocrine activations in two inbred strains (DBA/2J and CBA/J). J. Exp. Anim. Sci, 36, 101-116 (1994).

8. Hunt, C. \& Hambly, C. Faecal corticosterone concentrations indicate that separately housed male mice are not more stressed than group housed males. Physiol. Behav. 87, 519526 (2006).

9. Jennings, M. et al. Refining rodent husbandry: the mouse. Report of the Rodent Refinement Working Party. Lab. Anim. 32, 233-259 (1998).

10. Kingston, S.G. \& Hoffman-Goetz, L. Effect of environmental enrichment and housing density on immune system reactivity to acute exercise stress. Physiol. Behav. 60, 145-150 (1996).

11. Peng, X., Lang, C.M., Drozdowicz, C.K. \& OhlssonWilhelm, B.M. Effect of cage population density on plasma corticosterone and peripheral lymphocyte populations of laboratory mice. Lab. Anim. 23, 302-306 (1989).

12. Peters, A. \& Festing, M. Population density and growth rate in laboratory mice. Lab. Anim. 24, 273-279 (1990).

13. Renne, U. The effect of caging type and population density on the body weight development of laboratory mice. Z. Versuchstierkd. 32, 153-156 (1989).

14. Sherwin, C.M. Observations on the prevalence of nestbuilding in non-breeding T0 strain mice and their use of two nesting materials. Lab. Anim. 31, 125-132 (1997).

15. Smith, A.L. \& Corrow, D.J. Modifications to husbandry and housing conditions of laboratory rodents for improved well being. ILAR J. 46, 140-147 (2005).

16. Tsai, P.P., Stelzer, H.D., Hedrich, H.J. \& Hackbarth, H. Are the effects of different enrichment designs on the physiology and behaviour of DBA/2 mice consistent? Lab Anim. 37, 314-327 (2003).
17. Van de Weerd, H.A., Van Loo, P.L., Van Zutphen, L.F., Koolhaas, J.M. \& Baumans, V. Nesting material as environmental enrichment has no adverse effects on behavior and physiology of laboratory mice. Physiol. Behav. 62, 1019-1028 (1997).

18. Van de Weerd, H.A., Van Loo, P.L., Van Zutphen, L.F., Koolhaas, J.M. \& Baumans, V. Preferences for nesting material as environmental enrichment for laboratory mice. Lab. Anim. 31, 133-143 (1997).

19. Van Loo, P.L., Mol, J.A., Koolhaas, J.M., Van Zutphen, P.F. \& Baumans, V. Modulation of aggression in male mice: influence of group size and cage size. Physiol. Behav. 72, 675-683 (2001).

20. Wurbel, H. \& Stauffacher, M. Prevention of stereotypy in laboratory mice: effects on stress physiology and behaviour. Physiol. Behav. 59, 1163-1170 (1996).

21. Council of Europe. Council Directive 86/609/EEC: 0J L 358 , 18.12.1986 as last amended by Directive 2006-10/EC. Appendix II.

22. Fullwood, S., Hick, T.A., Brown, J.C., Norman, R.L. \& McGlone, J.J. Floor space needs for laboratory mice. ILAR J. 39, 29-36 (1998).

23. McGlone, J.J., Anderson, D.L. \& Norman, R.L. Floor space needs for laboratory mice: BALB/cJ males or females in solid-bottom cages with bedding. Cont. Topics 40, 21-25 (2001).

24. Smith, A.L., Mabus, S.L., Muir, C. \& Woo, Y. Effects of housing density and cage floor space on $\mathrm{C57BL} / 6 \mathrm{~J}$ mice. Comp. Med. 54, 656-663 (2004).

25. Smith, A.L., Mabus, S.L., Muir, C. \& Woo, Y. Effects of housing density and cage floor space on three strains of young adult inbred mice. Comp. Med. 55, 368-376 (2005).

26. Guide for the Care and Use of Laboratory Animals. (ILAR, National Academies Press, Washington, DC,1996).

27. Public Health Service. Policy on Humane Care and Use of Laboratory Animals. (US Department of Health and Human Services, Washington, DC, 1996) (PL 99-158, Health Research Extension Act, 1985).

28. United States Department of Agriculture. Animal Welfare Act and Animal Welfare Regulations, 9 CFR, Chapter 1 (USDA, Beltsville, MD, 1992).

29. Carbone, L. What Animals Want: Expertise and Advocacy in Laboratory Animal Welfare Policy. (Oxford University Press, New York, 2004).

30. White, W.J., Balk, M.W. \& Lang, C.M. Use of cage space by Guineapigs. Lab. Anim. 23, 208-214 (1989).

31. United States Department of Agriculture, Animal and Plant Health Inspection Service. Final Rule: Animal Welfare; Standards; 9 CFR Part 3. Federal Register, vol. 55, no. 32. February 15, 1991. P. 6426-6505.

32. Latham, N. \& Mason, G. From house mouse to mouse house: the behavioural biology of free-living Mus musculus and its implications for laboratory housing. Appl. Anim. Behav. Sci. 86, 261-289 (2004).

33. Whitten, W.K. Occurrence of anoestrus in mice caged in groups. J. Endocrinol. 18, 102-107 (1959).

34. Bouwknecht, J.A., Olivier, B. \& Paylor, R.E. The stress-induced hyperthermia paradigm as a physiological animal model for anxiety: a review of pharmacological and genetic studies in the mouse. Neurosci. Biobehav. Rev. 31, 41-59 (2007).

35. Festing, M.F. Design and statistical methods in studies using animal models of development. ILAR 47, 5-14 (2006).

36. Wurbel, H. \& Garner, J.P. Refinement of rodent research through environmental enrichment and systematic randomization. NC3Rs - National Centre for the Replacement, Refinement and Reduction of Animals in Research at <http:// www.nc3rs.org.uk/news.asp?id=395> (2007).

37. Whitaker, J. et al. The effect of cage size on reproductive performance and behavior in C57BL/6 mice. Lab Anim. (NY) 38, 32-39 (2007).

38. United States Department of Agriculture, Animal and Plant Health Inspection Service, Animal Welfare Enforcement. 
Fiscal Year 1997: Report of the Secretary of Agriculture to the President of the Senate and the Speaker of the House of Representatives, Appendix, Table 2. APHIS 41-35-054.

39. Council for Agricultural Science and Technology. Scientific Aspects of the Welfare of Food Animals Report 91 (Ames, Iowa, 1981).

40. Dawkins, M.S. Animal Suffering: The Science of Animal Welfare (Chapman \& Hall, London, 1980).

41. Duncan, I.J.H. Animal rights - animal welfare: a scientist's assessment. Poult. Sci. 60, 489-499 (1981).

42. Rollin, B.E. The Unheeded Cry: Animal Consciousness, Animal Pain and Science (Oxford University Press, New York, 1989).

43. Gärtner, K. et al. Stress response of rats to handling and experimental procedures. Lab. Anim. 14, 267-274 (1980).

44. Edwards, E.A. \& Dean, L.M. Effects of crowding mice on humoral antibody formation and protection to lethal antigenic challenge. Psychosom. Med. 39, 19-24 (1977).

45. Harvey, P.W. \& Chevins, P.F. Crowding during pregnancy delays puberty and alters estrous cycles of female offspring in mice. Experientia 43, 306-308 (1987).

46. Hurst, J.L., Barnard, C.J., Tolladay, U., Nevison, C.M. \& West, C.D. Housing and welfare in laboratory rats: Effects of cage stocking density and behavioural predictors of welfare. Anim. Behav. 58, 563-586 (1999).

47. Ishida, H., Mitsui, K., Nukaya, H., Matsumoto, K. \& Tsuji, K. Study of active substances involved in skin dysfunction induced by crowding stress. I. Effect of crowding and isolation on some physiological variables, skin function and skin blood perfusion in hairless mice. Biol. Pharm. Bull. 26, 170-181 (2003). 